\title{
Worker size in honeybees and its relationship with season and foraging distance
}

\author{
Romain SAUTHIER ${ }^{1}$, Robbie I'Anson PrICE ${ }^{1}$, Christoph GrÜTER ${ }^{1,2}$ \\ ${ }^{1}$ Department of Ecology and Evolution, Biophore, University of Lausanne, 1015, Lausanne, Switzerland \\ ${ }^{2}$ Institute of Zoology, Johannes Gutenberg University of Mainz, Johannes von Müller Weg 6, 55099, Mainz, Germany
}

Received 22 April 2016 - Revised 15 July 2016 - Accepted 16 August 2016

\begin{abstract}
Workers in many eusocial insect species show considerable size variation within a colony. Honeybees (Apis mellifera) vary little in size compared to other eusocial bee species, but there is evidence for a link between worker size and behaviour. In this study, we investigated how size variation and the average size of honeybee foragers change during a foraging season. We also tested the influence of colony weight and swarming on worker size. Finally, by analysing waggle dances, we tested if forager size is linked to foraging distance, between and within colonies. We found that the size of foragers significantly increases over the foraging season. Swarming did not appear to affect worker size, but colony size was overall positively linked to wing length and leg width. However, we did not find a relationship between foraging distance and forager size. We discuss how the constant size of brood cells and an efficient communication between foragers could lead to a narrower size range.
\end{abstract}

\section{Apis mellifera carnica / average worker size / body size variation / foragers}

\section{INTRODUCTION}

Many species of eusocial insects show size variation among the workers of a colony (Hölldobler and Wilson 2009). This variation allows colonies to establish a division of labour based on size (and shape) differences among workers. Examples of this can be seen in termites (Noirot and Pasteels 1987), stingless bees (Grüter et al. 2012), bumblebees (Goulson et al. 2002) and ants (Hölldobler and Wilson 1990). In eusocial bees, size variation is less pronounced (e.g. Oster and Wilson 1978), but examples of biologically relevant size variation exist. In the stingless bee Tetragonisca angustula, the guard, forager and

Electronic supplementary material The online version of this article (doi:10.1007/s13592-016-0468-0) contains supplementary material, which is available to authorized users.

Corresponding author: R. Sauthier, romain.sauthier@bluewin.ch Manuscript editor: Stan Schneider nest-cleaning workers differ in their morphology (Grüter et al. 2012; Hammel et al. 2016). Guards are the biggest worker type, and they have relatively larger legs, whereas foragers are smaller, but have relatively larger heads. In bumblebees (Bombini), workers show an even greater size variation: the biggest workers in a colony can be 10 times larger than the smallest workers (Couvillon and Dornhaus 2010). Larger workers preferentially perform foraging tasks, whereas smaller workers prefer within-nest tasks (Goulson et al. 2002; Jandt and Dornhaus 2009; Spaethe and Weidenmüller 2002).

Size and shape variation also appear within the task groups themselves (Ramalho, ImperatrizFonseca and Giannini 1998; Spaethe and Weidenmüller 2002). For instance, smaller foragers of the stingless bee Melipona quadrifasciata possess bigger corbiculae relative to their body size (Ramalho et al. 1998). Thus, it was argued that colonies with smaller bees might be able to increase the brood production rate and increase the colony population faster after a 
collapse due to a higher intake per worker (Ramalho et al. 1998). In many bumblebee species, large size variation among foragers can be found (Goulson et al. 2002; Peat, Tucker, and Goulson 2005; Spaethe and Weidenmüller 2002).

There are various proximate and ultimate reasons for size variation within colonies and among task groups in eusocial insects. In bees, variation in size can be caused by the position of a larva in the nest, as shown in the stingless bee Tetragonisca angustula (Segers et al. 2015) and the bumblebee Bombus impatiens (Couvillon and Dornhaus 2009). In these cases, the larvae are fed more generously in the central zone of the brood area than in the periphery. Colony size also affects worker size and size variation: in ants, an increase in colony size is often associated with an increase in both average worker size (Solenopsis invicta (Tschinkel 1988); Pogonomyrmex badius (Tschinkel 1998)) and worker size variation (leafcutter ants (Hölldobler and Wilson 2009)). Jandt and Dornhaus (2014) hypothesised that a larger worker size variation could be adaptive as differently sized workers could have a higher efficiency in different sets of tasks, and Peat et al. (2005) suggested that having a variable forager force could help colonies better exploit a wider range of food sources.

Honeybees Apis mellifera use an age-related, rather than a size-related division of labour (Hölldobler and Wilson 2009). Roulston and Cane (2000) found that A. mellifera shows the smallest variation in body size among the 31 bee species they studied. Waddington (1989) has suggested that a low size variation among foragers reduces mistakes during communication of foraging distances through the waggle dance. Thus, a small size variation among worker bees could have been selected to allow foragers to transmit vector information with more accuracy. Despite this, there is some size variation and it has been shown that worker size affects the age at which workers start foraging (Kerr and Hebling 1964).

Mean worker size could also affect colony success, and colonies might therefore be expected to adjust average worker size depending on ecological circumstances. For instance, colonies of the stingless bee Melipona flavolineata produce bigger workers when food stores increase (Veiga,
Menezes, Venturieri, and Contrera 2013). Bigger foragers are able to explore larger areas (Araújo, Costa, Chaud-Netto, and Fowler 2004; KuhnNeto, Contrera, Castro, and Nieh 2009), but carry lighter load of pollen per unit of weight than smaller bees do (Ramalho et al. 1998).

Foraging distances in A. mellifera increase from spring to summer before decreasing in fall (Couvillon, Schürch, and Ratnieks 2014), suggesting that summer is the most challenging season for honeybees in temperate European habitats in terms of finding food. Thus, it might be beneficial for colonies to produce larger bees during summer. This has been shown in the stingless bee Nannotrigona perilampoides, for which a twofold weight and size change was recorded over a season, mainly due to the protein content and the quantity of larval food varying across the year (Quezada-Euán et al. 2011). These observations show that colonies of various ant and bee species adjust and modify worker size variation and average size depending on factors such as colony size or food stores. The aim of the present study was to investigate worker size in the honeybee A. mellifera during the course of 8 months (March to October 2015). We asked whether changes in the mean body size and body size variation occur during the study period. We also tested if colony size or the occurrence of swarming affects body size. Finally, by decoding waggle dances, we looked at whether larger bees forage at greater foraging distances than smaller bees do. We predicted that both the size and size variation of foragers increase from early spring to summer as colonies grow and as they need to cover greater foraging distances. We also expected that bigger bees tend to forage further from the nest than smaller bees do.

\section{MATERIALS AND METHODS}

\subsection{Study sites}

The experiments were conducted between March and October 2015. Low temperatures mean that foraging activity before March and after October is very low in the study area. Colonies of A. mellifera carnica, located at the University of Lausanne campus $\left(46^{\circ} 31^{\prime}\right.$ $\left.\mathrm{N}, 6^{\circ} 34^{\prime} \mathrm{E}\right)$ and at Agroscope in Liebefeld $\left(46^{\circ} 55^{\prime} \mathrm{N}\right.$, 
$\left.7^{\circ} 25^{\prime} \mathrm{E}\right)$ in Switzerland, were studied. Bees were sampled from two apiaries in Lausanne situated $300 \mathrm{~m}$ from one another (these were called "rooftop" and "terrace") and one apiary in Liebefeld (about $79 \mathrm{~km}$ from Lausanne). All colonies were kept in wooden hive boxes with space to expand during the year and contained a naturally mated $A$. $m$. carnica queen. The three apiaries were surrounded by urban open spaces and agriculture crops. Bees could find a variety of flowers depending on the season and honeydew produced by aphids feeding on tree sap.

\subsection{Part 1: foragers' size change over the foraging season}

We sampled foragers from eight colonies from the rooftop apiary, five colonies from the terrace apiary and five colonies from the apiary in Liebefeld. Foragers returning to the colony were caught during the last week of every month between March and October. A minimum of 12 bees were collected per colony every month and stored in a freezer until they were measured.

Three measurements were taken from each bee: head width, right forewing length and the tibia width of the right hind leg. These measurements were used in previous experiments (Araújo et al. 2004; Bullock 1999; Cane 1987; Cueva del Castillo et al. 2015; QuezadaEuán et al. 2011; Roulston and Cane 2000), and they were preferred to dry mass because dry mass could be confounded by the crop content of workers. However, body mass is usually well correlated with many body parts such as the head capsule width and the forewing length (Bullock 1999; Spaethe and Weidenmüller 2002). The different parts were placed on laminated graph paper (to provide a size reference). Wings and legs were flattened under two microscope slides. Pictures were taken from directly above with a Nikon D5300 with a Nikon AF-S VR 60-mm macro lens. The measurements were performed with the program ImageJ (Abràmoff, Magalhães, and Ram 2004). A total of 12 bees were measured per colony and per month, except in June and July where a total of 24 bees per colony were measured (more bees were measured because these measurements were also used for part 2).

\subsection{Part 2: between-colony size variation}

This part studied the relationship between the average size of bees in a colony and the average foraging distance of bees in that colony. The experiment took place between the 3rd and the 7th of August. A week before the experiment, nine colonies were moved into observation boxes. These boxes were modified so that returning foragers were forced to enter and dance on the outer frame of the hive; this meant that they could be observed through a glass window (Figure 1). For each colony, 24 bees were caught and the head width was measured as described above. The bees were caught during the last week of July.

The visible frame was filmed (Panasonic HC-V130) for about $30 \mathrm{~min}$ per colony, in the morning (between 09:00 and 12:00 h) and afternoon (between 13:00 and 16:00 h) when foraging and dance activity were highest. The foraging distance was estimated using the waggle dance: the duration of a waggle run indicates the distance travelled by the bee (von Frisch 1967). Each second of waggle run corresponds to approximately $750 \mathrm{~m}$ (Schürch et al. 2013). Filmed dances were decoded using VLC program (Version 2.2.1) by calculating the average duration from four consecutive waggle runs, avoiding the first and last runs (Couvillon et al. 2012). The waggle run durations were analysed frame by frame ( $1 \mathrm{~s}=25$ frames).

\subsection{Part 3: within-colony size variation}

The final part studied the correlation between the size of individuals in a colony and foraging distances of these individuals. Three glass observation hives were set up in a wooden shed, each containing a queen, two brood frames, one honey frame and approx. 3000-4000

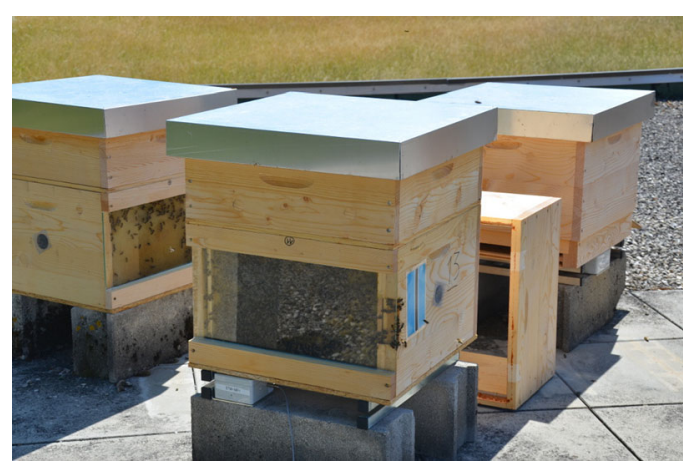

Figure 1. Observation hive on an automatic hive balance. The observation hive consists of a modified Dadant brood box and a standard Dadant honey box. Each brood box has a glass window on the side with a lateral entrance. 
workers (von Frisch 1967). A plastic tube connected the inside of the colony to the outside of the shed. Colonies were allowed to get used to their new environment for at least a week before the tagging of bees started. Between 400 and 600 bees per colony were tagged with numbered plastic discs (Opalith number tags). For this, bees were captured at the hive entrance (presumably foragers) and marked using queen marking devices. During the following days, tagged bees that were dancing were filmed for $1 \mathrm{~min}$. The relative foraging distances were estimated from the dance as in the previous part. After finishing a dance, the filmed bees were caught and their head width was measured. The bees from the three colonies were filmed and caught from the 27 th to the 31 st of August (colony 1), from the 7 th to the 11th of September (colony 2) and from the 29th of September to the 5 th of October (colony 3 ).

\subsection{Additional measurements: colony size}

To estimate colony size, we collected data on the colony weight. These data are available for all the colonies in Lausanne used in the first part. Colony weights were measured using BeeWatch hive scales ( \pm $20 \mathrm{~g}$ accuracy) placed under each colony (Figure 1). For part 1, weight data were collected on the 16th of each month at 1 a.m. For the second part, we took the colony weight on the 5 th of August at 3 a.m. The weight was taken during the night because all bees are inside the hive at this time. We used weight and weather data to confirm that our weight measurements were not confounded by rain.

\subsection{Statistical analysis}

Statistics were performed in R (R Core Team 2014). We used linear models (LMs) from the package "car" (Fox and Weisberg 2011) to test for correlations between the three body part measurements on each bee. We used linear mixed-effects models (LMEs) from the package "Ime4" (Bates, Maechler, Bolker, and Walker 2014)) for all other statistics. All response variables in the models were normally distributed. Colony was used as a random factor (Zuur, Ieno, Walker, Saveliev, and Smith 2009). Further pairwise comparisons were made with the function pairwise.t.test() from the package "stats" (R Core Team 2014) and Bonferroni correction.

Model II regression analyses (Quinn and Keough 2002) tested the relationships between the body parts.
We $\log _{10}$-transformed the measurements and used standard major axis regression. The slopes and $95 \%$ confidence intervals allowed us to test if the relationships between the variables are isometric or allometric. A relationship is allometric if the slope significantly differs from 1, i.e. 1 is not within the $95 \%$ confidence interval (Hölldobler and Wilson 2009).

For the first part, each combination of predictors was tested three times, using the three body measurements as response variables. We modelled the effects of "months" and "locations" (i.e. apiary ID) on the size measurement and on their coefficient of variation $(\mathrm{CoV})$. We tested the effect of months as a factor and also as a covariate in separate models. More precisely, when testing months as a factor, we tested for a difference in size measurements between any of the months, whereas when testing months as a covariate, we tested for a general trend (increase or decrease) across the months. Additionally, we tested the effects of colony size and of whether a colony swarmed in separate models because this information was available only for a subset of the colonies. We considered colonies to have swarmed after swarming took place and also if they were split to prevent natural swarming (performed in the presence of swarm cells). To test whether swarming affected body size measurements, we compared the body measurements from the month before swarming to measurements taken the three following months.

In the second part, we used LMEs to test whether the waggle run duration of bees from a colony was linked to the average head size of bees from that colony. For the last part, LMEs were performed to test if waggle run duration indicated by a dancer was correlated with the head width of the same dancer.

\section{RESULTS}

\subsection{Part 1: forager size changes over the foraging season}

The three body measurements were highly correlated (LME; head-wing $\chi^{2}{ }_{1}=558.86$, $P<0.0001$; head-leg $\chi_{1}{ }_{1}=204.65, P<0.0001$; wing-leg $\left.\chi^{2}{ }_{1}=237.74, P<0.0001\right)$. There was no interaction with location (LME; head-wing $\chi_{2}^{2}=2.1167, P=0.347$; head-leg $\chi_{2}^{2}=1.5043$, $P=0.471342$; wing-leg $\chi_{2}^{2}=1.6048$, $P=0.4483$ ). Thus, the relationships between the 
body parts are similar in all three locations. Our results also indicated that the relationship between the leg width and the head width was allometric (slope $=2.2$, CI 2.09-2.3), as well as the relationship between the leg width and the forewing length (slope $=2.08$, CI 1.99-2.18). The relationship between the head width and forewing length was isometric (slope $=1.05$, CI 1-1.09).

Using month as a factor, a significant interaction was found between the months and the locations for each body part (head $\chi^{2}{ }_{14}=55.5, P=<0.0001$; wing $\chi_{14}^{2}=27.5, P=0.0164$; leg $\chi_{14}^{2}=43.97$, $P<0.0001)$. Thus, the change in size during the season differed between locations. More precisely, the two apiaries in Lausanne show highly significant differences of bee size between the months (see Table I). This is not the case for the apiary in Liebefeld (except for the leg measurements, Table I). To explore the temporal effects further, we used month as covariate to test if there was a tendency of bees to increase in size during the study period. We found that the three body measurements significantly increased over the months (LME; head $\chi_{1}^{2}=16.705, P<0.0001$; wing $\chi^{2}{ }_{1}=11.456$, $P=0.0007$; leg $\chi^{2}{ }_{1}=7.1524, P=0.007$ ) (Figure 2). Subsequent analyses, exploring general patterns over the months, found no interaction between the month and the location (head $\chi_{2}^{2}=1.8578, P=0.395$; wing $\chi_{2}^{2}=4.9916$, $P=0.082$; leg $\chi_{2}^{2}=1.012, P=0.603$ ).

Comparisons between the apiaries showed that the head width was not significantly different

Table I. Chi-square values and $P$ values for the models testing the body part changes over the months (as factor) for each apiary.

\begin{tabular}{llcc}
\hline Apiary & Body part & $\chi^{2}$ values & $P$ values \\
\hline Rooftop & Head width & 24.087 & 0.0011 \\
Rooftop & Forewing length & 19.077 & 0.0079 \\
Rooftop & Hind leg width & 36.38 & $<0.0001$ \\
Terrace & Head width & 54.461 & $<0.0001$ \\
Terrace & Forewing length & 31.723 & $<0.0001$ \\
Terrace & Hind leg width & 35.043 & $<0.0001$ \\
Liebefeld & Head width & 10.678 & 0.15 \\
Liebefeld & Forewing length & 12.002 & 0.10 \\
Liebefeld & Hind leg width & 18.751 & 0.009 \\
\hline
\end{tabular}

between the apiaries $\left(\chi_{2}^{2}=2.7619, P=0.2513\right)$, but the forewing length $\left(\chi_{2}^{2}=27.942, P<0.0001\right)$ and the hind leg width $\left(\chi_{2}^{2}=8.9517, P=0.011\right)$ were. The colonies from the rooftop apiary in Lausanne have smaller wings and thinner legs whereas colonies from Liebefeld have longer wings (Table II). Hind leg width is not significantly different between the colonies from Liebefeld and the colonies from the terrace apiary in Lausanne, but colonies from Liebefeld have significantly wider legs than colonies from the rooftop apiary (Table II). Two colonies from the terrace apiary in Lausanne died in September and two colonies from the rooftop apiary died in October, reducing the sample size for these 2 months.

There was no significant relationship between the colony weight and the head width of bees from that colony $\left(\chi^{2}{ }_{1}=2.5037, P=0.1136\right.$; Figure 3$)$, but we did find a positive relationship between the colony weight and the forewing length $\left(\chi_{1}^{2}=5.5956, P=0.018\right)$, as well as the hind leg width $\left(\chi_{1}^{2}=7.4294, P=0.006\right)$.

The $\mathrm{CoV}$ for head width and wing length did not change over the months (head $\chi^{2}{ }_{1}=0.004$, $P=0.95$; wing $\chi^{2}{ }_{1}=0.30, P=0.58$ ), but the $\mathrm{CoV}$ for leg width decreased significantly $\left(\chi_{1}^{2}=3.9906, P=0.046\right)$. The $\mathrm{CoV}$ is also significantly different between the locations for the head width and the leg width measurements (head $\chi_{2}^{2}=14.18, P=0.0008$; leg $\chi_{2}^{2}=10.94$, $P=0.004)$. Bees from the Liebefeld apiary have lower variation than the bees from the terrace in Lausanne, who themselves had lower variation than the bees from the rooftop. However, only colonies from Liebefeld and the rooftop apiary are significantly different (Table III). The CoV for the forewing length was not significantly different between the locations (wing $\chi_{2}^{2}=0.4614$, $P=0.794)$.

Three colonies from the rooftop apiary in Lausanne and four colonies from Liebefeld swarmed during the time of the experiment (including both natural and artificial swarms). No significant change was found in the head and wing measurements in the months after swarming (head $\chi_{3}^{2}=2.7825, P=0.095$; wing $\chi_{3}^{2}=0.5715$, $P=0.45)$. However, a significant increase is observed for the leg measurements $\left(\chi_{3}^{2}=7.867\right.$, $P=0.005)$. 

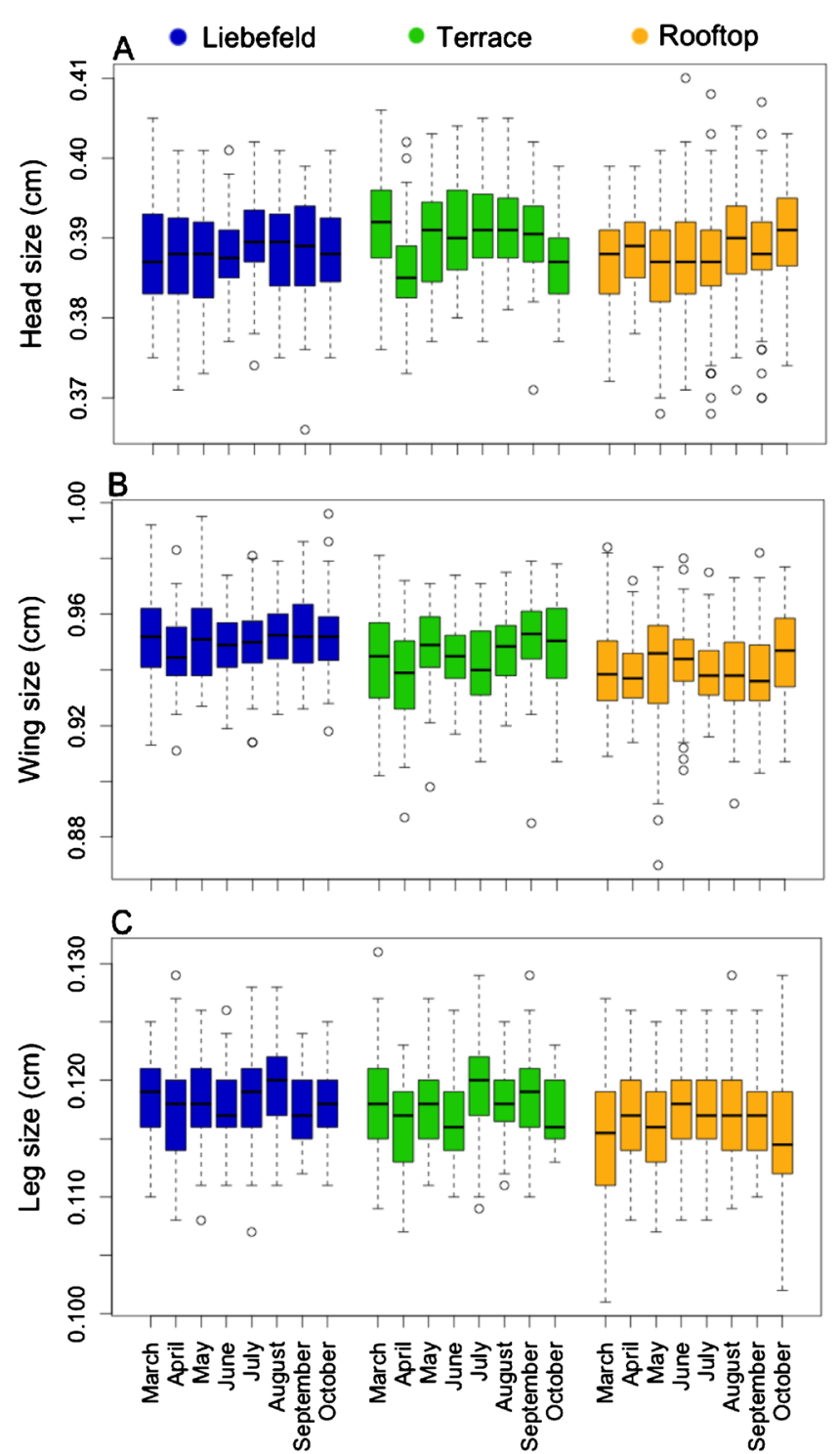

Figure 2. Head width (a), forewing length (b) and hind leg width (c) separated by apiaries and by months. Box plots on the left represent Liebefeld apiary (Liebefeld), in the middle represent the terrace apiary in Lausanne (Terrace) and on the right represent the rooftop apiary in Lausanne (Roof). The boxes indicate the data between the 25 and $75 \%$ quartiles including the median (black line); the whiskers represent the minimum and maximum values, outliers excluded (represented by open circles).

Table II. Pairwise $t$ test comparisons between the apiaries for forewing length and hind leg width.

\begin{tabular}{|c|c|c|c|c|}
\hline \multirow[t]{2}{*}{ Pairwise $t$ test comparisons } & \multicolumn{2}{|l|}{ Forewing } & \multicolumn{2}{|l|}{ Hind leg } \\
\hline & Liebefeld & Terrace & Liebefeld & Terrace \\
\hline Terrace & $<0.0001$ & - & 0.3 & - \\
\hline Rooftop & $<0.0001$ & $<0.0001$ & $<0.0001$ & 0.00013 \\
\hline
\end{tabular}




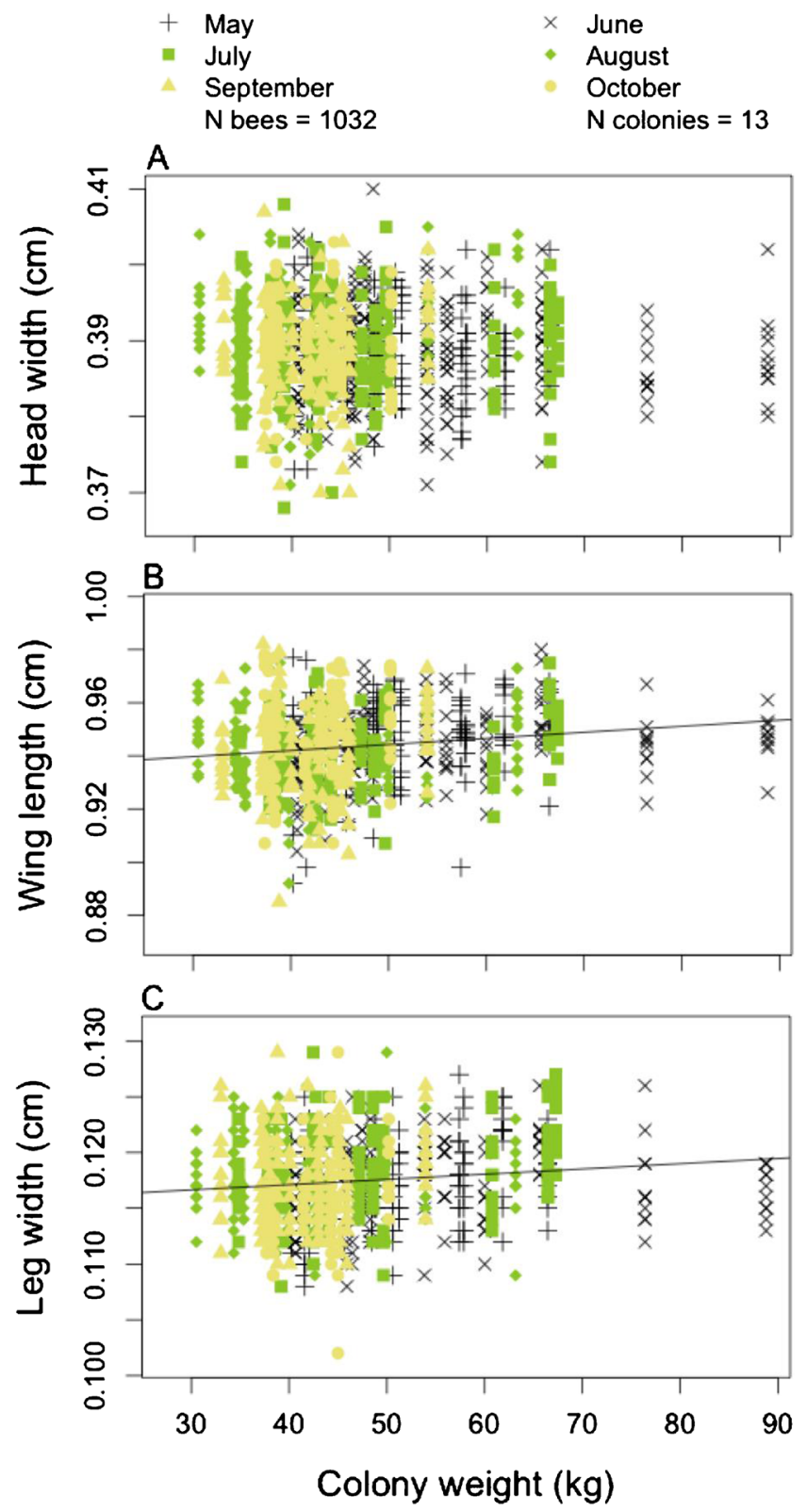

Figure 3. Relationship between the colony weights and respectively the head width (a), the wing length (b) and the leg width (c). Every month is represented by a colour and a shape (dark circle for May, dark triangle for June, grey circle for July, grey triangle for August, light circle for September and light triangle for October).

\subsection{Part 2: among-colony size variation}

In total, we decoded 206 dances for this part, but the number of dances that were recorded was variable among colonies (nine colonies, range $=6-$ 30 dances) (Table S1). We found no relationship between average worker size and the foraging distances indicated by dances $\left(\chi^{2}{ }_{1}=0.4769\right.$, $P=0.49$; Figure 4). The foraging distances indicated by the bees were not significantly different among the colonies (LM with colonies as predictor; $F_{8,197}=1.2109, P=0.29$ ). A total of 62 bees 
Table III. Pairwise $t$ test comparisons between the apiaries for head width and hind leg width CoVs.

\begin{tabular}{|c|c|c|c|c|}
\hline \multirow[t]{2}{*}{ Pairwise $t$ test comparisons } & \multicolumn{2}{|c|}{ Head width $\mathrm{CoV}$} & \multicolumn{2}{|c|}{ Hind leg width $\mathrm{CoV}$} \\
\hline & Liebefeld & Terrace & Liebefeld & Terrace \\
\hline Terrace & 0.194 & - & 0.1608 & - \\
\hline Rooftop & 0.001 & 0.182 & 0.0033 & 0.4857 \\
\hline
\end{tabular}

were filmed during the morning and 144 bees were filmed during the afternoon. Bees foraged significantly further during the morning $\left(\chi_{1}^{2}=5.1598, P=0.023\right)$. However, no relationship was found between average worker size and the foraging distances for both the morning $\left(\chi_{1}^{2}=1.0868, P=0.297\right)$ or the afternoon $\left(\chi_{1}^{2}=0.0724, P=0.788\right)$. When we only took into account the five colonies for which weight data was available, we observed that colony weight $\left(\chi^{2}{ }_{1}=0.0006, P=0.98\right)$ did not influence foraging distance.

\subsection{Part 3: within-colony size variation}

We analysed head width and dance behaviour of 88 bees to test if they correlate $(35,34$ and 19 bees respectively in the three observation hives). The duration of the waggle runs was very variable, with some lasting less than $0.4 \mathrm{~s}$ and some more than $2 \mathrm{~s}$. The waggle run durations were not significantly different among the colonies (LM with colonies as predictor; $F_{2,85}=0.1471$, $P=0.8634)$, with a mean \pm SD of $1.25 \pm 0.48 \mathrm{~s}$. Head widths did not differ between colonies (LM with colonies as predictor; $F_{2,85}=0.39$, $P=0.68)$. The mean \pm SD head size of the measured bees was $0.3930 \pm 0.00534 \mathrm{~cm}$ $(N=88)$. The size of the bees had no effect on the indicated foraging distance $\left(\chi^{2}{ }_{1}=0.57\right.$, $P=0.45$; Figure 5).

\section{DISCUSSION}

Our results show an increase in size of honeybee workers over the foraging season for all three measurements. However, not all months follow this pattern. For example, bees collected in March from the terrace colonies were larger than bees collected in April (Figure 2). Due to the long lifespan of winter bees (Fukuda and Sekiguchi 1966; Smedal et al. 2009), it is possible that the bees collected in March were actually winter bees that emerged the year before. The general

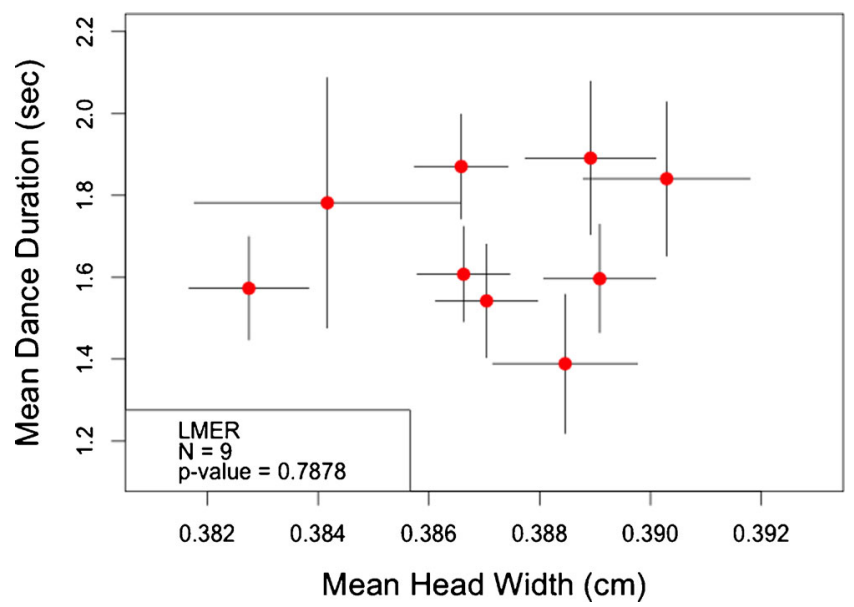

Figure 4. Mean foraging distance (represented by the dance duration in seconds) as a function of the mean head width \pm SE (cm). 


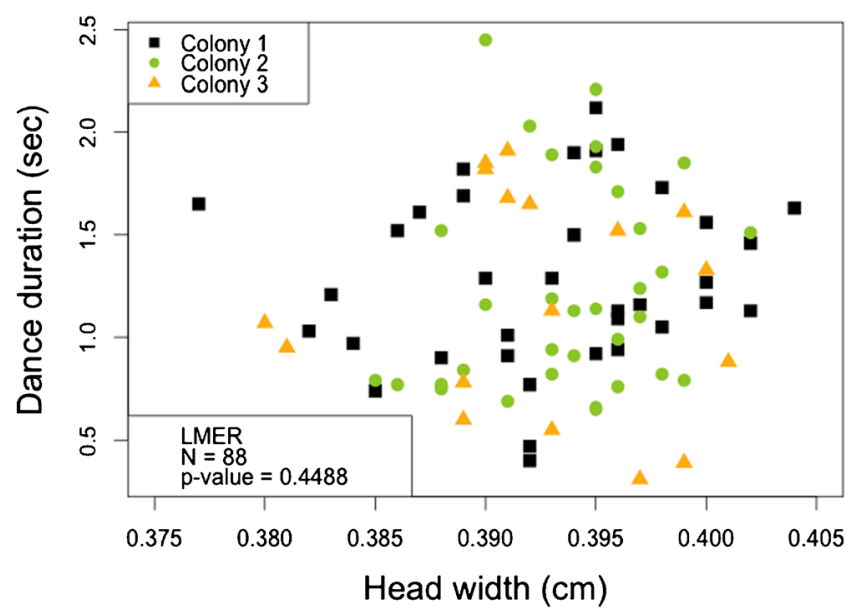

Figure 5. Foraging distances (represented by the dance duration in second) in function of the head width (cm). The three different colonies are represented by black squares, circles, and triangles .

tendency of bees to become bigger could be biologically significant, for example because the foraging distances travelled by honeybees increase from spring to summer when food sources are more difficult to find (Couvillon et al. 2014) and larger bees might be able to fly further (Araújo et al. 2004; Greenleaf et al. 2007; Kuhn-Neto et al. 2009). However, it is noteworthy that the size increase was small: a maximum average size increase of 0.6, 0.52 and $1.3 \%$ occurred from April to August for the head width, the forewing length and the tibia width measurements respectively. In stingless bees, a maximum average size increase of around $5.5 \%$ occurred between November and May (Quezada-Euán et al. 2011). This underlines that honeybee colonies maintain a very narrow size range compared to other bee species. The $\mathrm{CoV}$ did not change over time, which suggests that size variation is constant over time in honeybees.

In some stingless bee species such as Melipona quadrifasciata (Ramalho et al. 1998) or Melipona flavolineata (Veiga et al. 2013), it was shown that smaller workers have larger corbiculae relative to their body size and are able to carry heavier loads of pollen per unit of body than larger bees. Our results indicate the opposite in honeybees: larger bees have relatively larger legs and probably larger corbiculae than smaller bees. Bigger bees could be produced to carry relatively higher loads of pollen and increase food stores faster during periods with poor foraging conditions in summer.

We found that the forewing length and hind leg width are positively correlated with the colony weight. This is not the case for the head width despite its strong correlation with the wing and leg size. In the stingless bees, species Tetragonisca angustula and Melipona quadrifasciata colony size and bee size are also positively correlated (Ramalho et al. 1998; Segers et al. 2016). In honeybees, larger colonies might produce foragers with wider legs to enable foragers to bring back more pollen if larger colonies rear relatively more brood. It would be interesting to test if the relative investment in brood depends on colony size and if the quantity and composition of larval food change during the season.

The size of the colony drastically decreases when a swarm takes off. Given the potential relationship between colony size and worker size (Segers et al. 2016), we expected the size of bees to decrease after swarming. In our study, we found that the size of bees was similar before and after the colonies swarmed for the head and forewing measurements. However, an increase in hind leg width measurements was observed. This could be attributed to the rapid recovery of colony size that usually occurs after swarming and the global increase in bee size over time. Overall, our results suggest that the 
effect of swarming on the size of honeybees in the colony is negligible.

We found no evidence that colonies with larger foragers tend to forage further from the nest than do colonies with smaller foragers. Such a correlation has been found both among bee species (Araujo et al. 2004) and within bee species (Kuhn-Neto et al. 2009). It is possible that our colonies were not sufficiently different in worker size or that the number of dances recorded was too low or bee size might simply not affect foraging distance in A. mellifera . Our results also show no significant relationship between colony size (represented here by colony weight) and foraging distance. Beekman et al. (2004) found that small and large colonies foraged at similar distances in July when food was abundant, but larger colonies tended to go further in August when food was scarce (Beekman et al. 2004). Our measurements were taken at the beginning of August when colonies were not producing a lot of honey. Beekman et al. (2004) included very small colonies, whereas we studied natural colony size variation among colonies. Future studies should also include measuring forewing length and hind leg width, as both correlated with colony size. Also, when exploring intra-colonial size variation, we found no evidence that the size of foragers influenced the foraging distance. Thus, it remains unclear whether the increase in size during the season has an effect on foraging behaviour and performance. It is possible that larger bees forage at a higher rate, as shown in bumble bees (Spaethe and Weidenmüller 2002) or that larger bees might be less likely to suffer from predation. Alternatively, the production of slightly bigger bees in summer could simply be a side-effect of the accumulation of resources during spring and increased larval food quantity. Finally, foraging distances might be needed to observe a correlation between worker size and foraging distance. The foraging distances we measured are not unusual compared to previous studies (Beekman et al. 2004; Couvillon et al. 2014; Steffan-dewenter and Kuhn 2003), but under certain conditions foraging distances can be substantially greater (Beekman and Ratnieks 2000) and it would be interesting to observe the role of worker size under these unusual conditions.
In honeybees, genetic variation among workers due to multiple mating by the queens is much higher than in most other social insects (Strassmann 2001). Multiple mating is linked to size variation in other insects, like leaf-cutter ants (Evison and Hughes 2011). Furthermore, it is assumed that colonies would benefit from adjusting colony demography according to changes in ecological circumstances (e.g. Oster and Wilson 1978; Segers et al. 2016; Yang et al. 2004). This raises the question why honeybee colonies express so little size variation. The reason could be that honeybees build brood cells of very even size and re-use cells for multiple worker generations, which might limit both size variation and changes in mean size of the individuals during the year. The size of brood cells is tightly correlated with the size of the emerging individuals in several bee species (Couvillon and Dornhaus 2009; Segers et al. 2015). Stingless bees, on the other hand, are more flexible in the size and size variation of workers that are produced (Quezada-Euán et al. 2011; Segers et al. 2015, 2016; Veiga et al. 2013) because they do not re-use brood cells, but build new cells throughout the breeding cycle (Sakagami 1982). Another reason might be that honeybees are able to maintain constant temperatures inside the nest (Jones, Myerscough, Graham, and Oldroyd 2004): constant temperatures could lead to constant rearing conditions and induce the production of similarly sized workers (Kamm 1974). Stingless bees are less able to control the nest climate (Vollet-Neto, Menezes, and ImperatrizFonseca 2015). Finally, honeybees use a sophisticated form of communication for recruitment to food sources (Couvillon 2012; I'Anson Price and Grüter 2015; von Frisch 1967), which could select for low levels of variation among the foragers if recruitment efficiency is affected by size variation (Waddington et al. 1986). The adaptive significance of worker size variation in most social insect species remains unclear, but further research on the links between worker size and task performance in honeybees (e.g. pollen load capacity, foraging rate) might reveal if the narrow size range of workers is an advantage or a constraint. 


\section{ACKNOWLEDGMENTS}

We thank Philipp Engel and Thomas Richardson who allowed us to collect data from their respective colonies at the University of Lausanne, as well as Benoit Droz and the Agroscope in Liebefeld for the colonies in Liebefeld. We also thank Olivier Emery who helped during the experiments and Nicolas Vial for data collection in Liebefeld. C.G. and R.I.P. were funded by an Ambizione Fellowship from the Swiss National Science Foundation to C.G. (PZOOP3_142628/1).

Taille des ouvrières d'abeilles, en relation avec la saison et la distance d'approvisionnement

\section{Apis mellifera carnica / taille moyenne / ouvrière / varia- tion / butineuse}

\section{Die Beziehung der Grösse von Honigbienen zu Jahreszeit und Sammeldistanz}

\section{Apis mellifera carnica / mittlere Arbeiterinnengrösse / Variation der Körpergrösse / Sammlerinnen}

\section{REFERENCES}

Abràmoff, M. D., Magalhães, P. J., Ram, S. J. (2004). Image processing with image. J Biophotonics Int. $11(7), 36-41$.

Araújo, E. D., Costa, M., Chaud-Netto, J., Fowler, H. G. (2004). Body size and flight distance in stingless bees (Hymenoptera: Meliponini): inference of flight range and possible ecological implications. Brazilian J. Biol., 64 (3B), 563-568.

Bates, D., Maechler, M., Bolker, B., Walker, S. (2014). lme4: Linear mixed-effects models using Eigen and S4_._lme4: Linear Mixed-Effects Models Using Eigen and S4_. R Package Version 1.1-7, <URL: http://CRAN.R-project.org/package=lme4>.

Beekman, M., Ratnieks, F. L. W. (2000). Long-range foraging by the honey-bee, Apis mellifera L. Funct. Ecol., 14, 490-496.

Beekman, M., Sumpter, D. J. T., Seraphides, N., Ratnieks, F. L. W. (2004). Comparing foraging behaviour of small and large honey-bee colonies by decoding waggle dances made by foragers. Funct. Ecol., 18 (6), 829835.

Bullock, S. H. (1999). Relationships among body size, wing size and mass in bees from a tropical dry forest in Mexico. J. Kansas Entomol. Soc., 72 (4), 426-439.

Cane, J. H. (1987). Estimation of bee size using intertegular span (Apoidea). J. Kansas Entomol. Soc., 60 (1), 145147.
Couvillon, M. J. (2012). The dance legacy of Karl von Frisch. Insectes Soc., 59(3), 297-306.

Couvillon, M. J., Dornhaus, A. (2009). Location, location, location: larvae position inside the nest is correlated with adult body size in worker bumble-bees (Bombus impatiens ). Proc. R. Soc. London B Biol. Sci., rspb2009. doi: $10.1098 / \mathrm{rspb} .2009 .0172$

Couvillon, M. J., Dornhaus, A. (2010). Small worker bumble bees (Bombus impatiens) are hardier against starvation than their larger sisters. Insectes Soc., $57(2)$, 193-197.

Couvillon, M. J., Pearce, R., Fiona, C., Harris-Jones, E. L., Kuepfer, A. M., Mackenzie-Smith, S. J., Ratnieks, F. L. W. (2012). Intra-dance variation among waggle runs and the design of efficient protocols for honey bee dance decoding. Biol. Open, BIO20121099. doi:10.1242/bio.20121099

Couvillon, M. J., Schürch, R., Ratnieks, F. L. W. (2014). Waggle dance distances as integrative indicators of seasonal foraging challenges. PLoS One, 9(4), e93495. doi:10.1371/journal.pone.0093495

Cueva del Castillo, R., Sanabria-Urbán, S., SerranoMeneses, M. A. (2015). Trade-offs in the evolution of bumblebee colony and body size: a comparative analysis. Ecol. Evol., 5 (18), 3914-3926.

Evison, S. E. F., Hughes, W. O. H. (2011). Genetic caste polymorphism and the evolution of polyandry in Atta leaf-cutting ants. Naturwissenschaften, $98(8), 643-$ 649.

Fox, J., Weisberg, S. (2011). An $\{\mathrm{R}\}$ companion to applied regression, second edition. Thousand Oaks CA: Sage. URL: http://socserv.socsci.mcmaster.ca/jfox/Books/ Companion.

Fukuda, H., Sekiguchi, K. (1966). Seasonal change of the honeybee worker longevity in Sapporo, North Japan, with notes on some factors affecting the life-span. Jpn J Ecol, 16, 206-212.

Goulson, D., Peat, J., Stout, J. C., Tucker, J., Darvill, B., Derwent, L. C., Hughes, W. O. H. (2002). Can alloethism in workers of the bumblebee, Bombus terrestris, be explained in terms of foraging efficiency? Anim. Behav., 64 (1), 123-130.

Greenleaf, S. S., Williams, N. M., Winfree, R., Kremen, C. (2007). Bee foraging ranges and their relationship to body size. Oecologia, 153 (3), 589-596.

Grüter, C., Menezes, C., Imperatriz-Fonseca, V. L., Ratnieks, F. L. W. (2012). A morphologically specialized soldier caste improves colony defense in a neotropical eusocial bee. Proc. Natl. Acad. Sci., 109 (4), 1182-1186.

Hammel, B., Vollet-Neto, A., Menezes, C., Nascimento, F. S., Engels, W., Grüter, C. (2016). Soldiers in a stingless bee: work rate and task repertoire suggest they are an elite force. Am. Nat., 187 (1).

Hölldobler, B., Wilson, E. O. (1990). The Ants. Harvard University Press.

Hölldobler, B., Wilson, E. O. (2009). The superorganism: the beauty, elegance, and strangeness of insect societies. WW Norton \& Company. 
I'Anson Price, R., Grüter, C. (2015). Why, when and where did honey bee dance communication evolve? Front. Ecol. Evol., 3. doi:10.3389/fevo.2015.00125

Jandt, J. M., Dornhaus, A. (2009). Spatial organization and division of labour in the bumblebee Bombus impatiens. Anim. Behav., 77 (3), 641-651.

Jandt, J. M., Dornhaus, A. (2014). Bumblebee response thresholds and body size: does worker diversity increase colony performance? Anim. Behav., 87, 97106.

Jones, J. C., Myerscough, M. R., Graham, S., Oldroyd, B. P. (2004). Honey bee nest thermoregulation: diversity promotes stability. Science, 305 (5682), 402-404.

Kamm, D. R. (1974). Effects of temperature, day length, and number of adults on the sizes of cells and offspring in a primitively social bee (Hymenoptera: Halictidae). J. Kansas Entomol. Soc., 8-18.

Kerr, W. E., Hebling, N. J. (1964). Influence of the weight of worker bees on division of labor. Evolution, 18 (2), 267-270.

Kuhn-Neto, B., Contrera, F. A. L., Castro, M. S., Nieh, J. C. (2009). Long distance foraging and recruitment by a stingless bee, Melipona mandacaia. Apidologie, 40 (4), 472-480.

Noirot, C., Pasteels, J. M. (1987). Ontogenetic development and evolution of the worker caste in termites. Experientia, 43 (8), 851-860.

Oster, G. F., Wilson, E. O. (1978). Caste and ecology in the social insects. Princeton University Press.

Peat, J., Tucker, J., Goulson, D. (2005). Does intraspecific size variation in bumblebees allow colonies to efficiently exploit different flowers? Ecol. Entomol., 30, 176-181.

Quezada-Euán, J. J. G., López-Velasco, A., Pérez-Balam, J., Moo-Valle, H., Velazquez-Madrazo, A., Paxton, R. J. (2011). Body size differs in workers produced across time and is associated with variation in the quantity and composition of larval food in Nannotrigona perilampoides (Hymenoptera, Meliponini). Insectes Soc., 58 (1), 31-38.

Quinn, G. P., Keough, M. J. (2002). Experimental design and data analysis for biologists. Cambridge University Press.

R Core Team. (2014). R: A language and environment for statistical computing. R Foundation for Statistical Computing. Vienna, Austria. Retrieved from http:// www.r-project.org/

Ramalho, M., Imperatriz-Fonseca, V. L., Giannini, T. C. (1998). Within-colony size variation of foragers and pollen load capacity in the stingless bee Melipona quadrifasciata anthidioides Lepeletier (Adipae, Hymenoptera). Apidologie 29 (3), 221-228.

Roulston, T. H., Cane, J. H. (2000). The effect of diet breadth and nesting ecology on body size variation in bees (Apiformes). J. Kansas Entomol. Soc., 73 (3), 129-142.

Sakagami, S. F. (1982). Stingless bees. In: H. R. Hermann (Ed.) Social insects (vol. 3), pp. 361-423. Academic Press, New York.

Schürch, R., Couvillon, M. J., Burns, D. D. R., Tasman, K., Waxman, D., Ratnieks, F. L. W. (2013). Incorporating variability in honey bee waggle dance decoding improves the mapping of communicated resource locations. J. Comp. Physiol. A, 199 (12), 1143-1152.

Segers, F. H. I. D., Menezes, C., Vollet-Neto, A., Lambert, D., Grüter, C. (2015). Soldier production in a stingless bee depends on rearing location and nurse behaviour. Behav. Ecol. Sociobiol., 69 (4), 613-623.

Segers, F. H. I. D., von Zuben, L., Grüter, C. (2016). Local differences in parasitism and competition shape defensive investment in a polymorphic eusocial bee. Ecology 97 (2), 417-426

Smedal, B., Brynem, M., Kreibich, C. D., Amdam, G. V. (2009). Brood pheromone suppresses physiology of extreme longevity in honeybees (Apis mellifera). J. Exp. Biol., 212 (23), 3795-3801.

Spaethe, J., Weidenmüller, A. (2002). Size variation and foraging rate in bumblebees (Bombus terrestris). Insectes Soc., 49 (2), 142-146.

Steffan-Dewenter, I., Kuhn, A. (2003). Honeybee foraging in differentially structured landscapes. Proc. R. Soc. B, 270, 569-575.

Strassmann, J. (2001). The rarity of multiple mating by females in the social Hymenoptera. Insectes Soc., $48(1), 1-13$.

Tschinkel, W. R. (1988). Colony growth and the ontogeny of worker polymorphism in the fire ant, Solenopsis invicta . Behav. Ecol. Sociobiol., 22 (2), 103-115.

Tschinkel, W. R. (1998). Sociometry and sociogenesis of colonies of the harvester ant, Pogonomyrmex badius: worker characteristics in relation to colony size and season. Insectes Soc., 45, 385-410.

Veiga, J. C., Menezes, C., Venturieri, G. C., Contrera, F. A. L. (2013). The bigger, the smaller: relationship between body size and food stores in the stingless bee Melipona flavolineata. Apidologie, 44 (3), 324-333.

Vollet-Neto, A., Menezes, C., Imperatriz-Fonseca, V. L. (2015). Behavioural and developmental responses of a stingless bee (Scaptotrigona depilis) to nest overheating. Apidologie, 46 (4), 455-464. 
von Frisch, K. (1967). The dance language and orientation of bees. Cambridge, MA, US: Harvard University Press.

Waddington, K. D. (1989). Implications of variation in worker body size for the honey bee recruitment system. J. Insect Behav., 2 (1), 91-103.

Waddington, K. D., Herbst, H., Roubik, D. W. (1986). Relationship between recruitment systems of stingless bees and within-nest worker size variation. J. Kansas Entomol. Soc., 59(1), 95-102.

Yang, A. S., Martin, C. H., Nijhout, H. F. (2004). Geographic variation of caste structure among ant populations. Curr. Biol., 14 (6), 514-519. doi: 10.1016/j

Zuur, A., Ieno, E. N., Walker, N., Saveliev, A. A., Smith, G. M. (2009). Mixed effects models and extensions in ecology with R. Springer Science \& Business Media. 